\title{
Cost-effectiveness of models of care quality for children affected by HIV and AIDS in Nepal
}

- Pradhan PM, ${ }^{1}$ Bhatta G, ${ }^{2}$ Bam $K^{3}$

${ }^{1} \mathrm{BPH}, \mathrm{MPPG},{ }^{2} \mathrm{MBBS}$, Kathmandu University School of Medical Sciences, KU, Nepal ${ }^{3} \mathrm{BPH}$, HIV/AIDS Program Officer, Association of Medical Doctors of Asia (AMDA), Primary Health Care Project for Bhutanese Refugee

\begin{abstract}
Background:

With an estimated sixty four thousand people living with HIV in Nepal, there are tremendous implications for children, whose lives are greatly affected when a parent is infected. The objective of this study is to identify and assess cost effectiveness for existing models of care for children affected with HIV/AIDS
\end{abstract}

\section{Methods:}

The study performed cost effective analysis for types of care and support for children affected by HIV and AIDS in Nepal from a societal perspective. Types of care and support to Children affected by HIV/AIDS were assessed, Comparator minimum was estimated based on government minimum standards guideline; comparative analysis for cost effectiveness was done in terms of care quality, and overall modes of care delivery.

\section{Results:}

This study identified only three types of care model (comprehensive institutional model of care, home based care and support, community based care with income generation) prevalent in Nepal. Out of this three types of models of care: Community based care with income generation was assessed as the most cost effective care model in Nepal.

\section{Conclusion:}

Community based care with income generation imparted children with better socialization and professional skills. However, continuum of care was often missed by one model, therefore other existing models of child care were also essential to provide care and provision of safety nets for children who fail to reach the care homes should also be considered by the government.

Keywords: Comparative effectiveness, Cost effectiveness, Care models, Children affected by HIV/AIDS, CABA, Nepal.

\section{Background}

Nepal has concentrated epidemic of HIV and AIDS. The national adult prevalence of HIV is at $0.39 \%$. (1) It is estimated that currently 63,528 people are living with HIV in Nepal1. It has also been estimated of 4700 deaths in adults and children as of 2009 whose low and high estimates are 3800-57001. However, given the limitations of Nepal's public health surveillance system, the actual number of infections is thought to be much higher. (2) This concentrated epidemic still seems to be concentrated in 15-49 year age group. The disability and death of this economically productive age group poses serious threat to dependent population of children. Not only are children orphaned by AIDS affected by the virus, but those who live in homes that have taken in orphans, children with little education and resources, and those living in areas with high HIV rates are also impacted. (3)

Children account for half of all the new HIV infections worldwide and it is estimated that approximately four thousand children in Nepal are infected with HIV. (4) There are tremendous implications for children, whose lives are greatly affected when a parent is infected. (4) Estimates indicate that 2,500 children aged 0-14 are currently infected with HIV5.According to the national estimates of NCASC, 2009; there has been significant rise in the proportion of children infected with HIV and AIDS. (6) In 2009 the estimated cumulative number of orphans was 22,000 up from 11,000 in 2006.

At present a limited number of models of care for Children Affected by HIV and AIDS (CABA) exist in Nepal. As the number of orphans' increases these models will have to be expanded and even newer method of care may be made available. (7) Quality and costs of care provided by these different models, differs. In realm of effective and efficient planning, the relation between quality and costs of care provided by various models presently available in Nepal needs to be more clearly understood.

Interim constitution of Nepal-2007 has made special provisions for children of Nepal under clause 22, 5 subclauses are directly related to child rights.(8) According to the national Census 2001, Nepal's total population is $23,151,4239$. Out of which 909,821 population are under 14

CORRESPONDENCE: Prajwal Mani Pradhan, BPH, MPPG. Email: prajwalmanipradhan@gmail.com 
years this is $39.30 \%$ of the total population. (9) Planned development of Nepal has been started from 1950s, there has been no separate policy regarding child care in-spite of this there has been keen focus on child health since B.S. 2033 (1977 A.D.). (5) The only hospital for children is Kanti Hospital where as the number of pediatric doctors has increased to 95 . (5)

Based on these compelling statistics for children and their rights-no child should be left out. On the contrary, children affected with HIV and AIDS have appeared to be a least priority of child right programs. In conjunction with rights, a relation between various models of care quality has been observed with economic cost in this study. This study addresses both quality and cost of providing care in a comparative purview. This study is aimed to understand what was required for good quality care and minimum care of CABA as well as which models of care was the most cost-effective in Nepalese context.

This study uses the term Children Affected by HIV and AIDS(CABA) as those children under the age of 15 who has lost his/her biological parent both or one of them due to HIV and AIDS and now is/are currently either living with or without HIV and AIDS but is prone to stigma, discrimination from society. This report attempts on providing a primary foothold upon child rights especially children affected with HIV and AIDS through an economic perspective. The sites included were selected from both rural and urban settings coupled with HIV prevalence.

\section{Objectives}

This study consisted of two sequential phases. First, assessment for types of care and support to CABA was assessed. Second, variations in cost for various approaches and options were compared. The broad aim of study was to provide program managers with comparative economic evidence for care of CABA in Nepal. To that end, the study aimed to attain following specific objectives:

- Identify existing types of care and support for the children affected by HIV/AIDS in Nepal.

- Establish the cost of providing a minimum standard of quality care per child per month for each model according to government minimum standard guidelines.

- Determine options within these existing care models.

- Examine variations in costs between different options of care using cost-effective analysis.

\section{Method}

The study was completed in two sequential steps:

\subsection{Phase one: Assessment of types of care and support to Children affected by HIV/AIDS}

In this initial step, various relevant studies related with child care models, policies and practices were reviewed. Interestingly, we found that government of Nepal had prepared a final draft (only awaiting for implementation) of "Minimum standard working guideline for HIV/AIDS infected child care homes, 2009" (10) and "Minimum standard for conduction and management of child home" (11) these were particularly helpful in terms of identifying and establishing essential elements for care. Being from the government itself, we adopted the same minimum standard care elements for our study.

Consecutively, series of consultative meetings with child right activist, representative of various child care homes was done; this consultation step drastically reduced our time to identify child care homes/institutions because of "overlapping members"(member of one institution would also be member of another one or more institution). Additionally, consultation of minimum standard of care was also undertaken with same experts. Based on literature review and discussions various institutions were identified and categorized into appropriate models of care; categorization of care model was done with prior permission from the organizations themselves. Selection of particular child care sites followed stratified random sampling (consent for participation was taken verbally before starting the study in each institution, since institutions had to disclose their financial information) thus, representing various approaches to CABA care. Hence, they are representative of what is happening for the care of CABA in Nepal. Details of sample inclusion, exclusion criteria were:

\section{Inclusion criteria}

- The child care model should be providing or supporting child care to at least ten children living with HIV/AIDS.

- Services should be operational for at least one year before the study.

- Sites selection to represent rural and urban settings.

- Sites to represent formal structures and informal structures.

\section{Exclusion criteria}

- Child care model which does not address care of children living with HIV/AIDS.

- Institutions which do not want to share their financial information for this study.

Following the checklist, interview guidelines and observational checklist were developed by the authors then we compiled case portfolio for each site. Each site offered different insights emanating from the diverse pool of opportunities they were working on.

\subsection{Phase two: Cost-effectiveness analysis}

This phase calculated economic costs for care quality in care 
providing institutions, minimum standards of care and Cost Effectiveness Analysis (CEA). CEA assesses the type of service that is likely to be most beneficial and appropriate with given resources. This analysis was then combined with detailed study for quality of care provided by each care model. The combined output provided a useful tool for making policy decision, allocation of resources towards care of CABA in Nepal.

We have used direct and opportunity costs (12) which are equal to the value of best available alternative use of resources. For example volunteer's time has no financial implications for the organization, this time could be invested elsewhere to generate value. Since quality of this care varies substantially between models (with some not even providing a minimum standard of care) an analysis of cost per childcare month would therefore misrepresent the situation. The perspective of this analysis is from society as a whole, rather than from an organization or individual. The present value 12 of fixed cost item were calculated using $\mathrm{Pt}=\mathrm{Po}(1+\mathrm{r}) \mathrm{t}$ [where, $\mathrm{Pt}=$ present time price, $\mathrm{Po}=$ Purchase price, $\mathrm{r}=$ Discount rate, $\mathrm{t}=$ Useful time]. After obtaining a present time price, the present time price was divided by the annualization factor 12 .

The effectiveness measure for this study could be number of months/year a child is cared for, multiplied by number of children. But, this effectiveness measure then would not account quality of care provided by each model of care. Therefore, the identification of effectiveness measure for this study was drawn from a similar South African study conducted by Desmond et al. (2002), where he argues that this problem could be solved by measuring both the actual costs of the programs and the cost that would be incurred in providing the minimum standard of care. Taking this into consideration, each site was tagged with two costs: cost of providing care per child care month and cost of providing a minimal standard of care. Since, most of child care homes were running in leased buildings, it was essential for the authors to construct another minimum standard of care using rental values, as government minimum standard of care stressed upon running on institutionally owned building. Sole comparison with government minimum standard of care therefore would also misinterpret the situation. Therefore, two comparator minimum standards were constructed to broaden generalizability and applicability of this study. Two comparator minimum standards were: minimum standard (with house rent) and minimum standard (with house owned). The minimum standard of care consisted of government guidelines along with basic consumptions, safe and secure housing, care givers time and access to services (health and education). The summary of minimum standard care:

\subsection{Minimum standard of care}

Nepal Government's "Minimum standard for conduction and management of child home" (11) and "Minimum standard working guidelines for HIV infected child care homes" (10) jointly formed a basis for costing of minimum standard of care. For practicality, statistically averaged values have been used only where the authentic estimates by government were not available (For e.g: number of stationeries required per month or year etc.) However, this should not be interpreted with understanding of minimum standard as an "Average Value". Minimum standard should be understood not as a top-notch standard, but as a standard of which when met creates a situation where children have as minimum access towards opportunities compared to those of children living with their parents without HIV/AIDS have. Simply put, it is a means for achieving equal accessibility to rightfully respected living.

Some of governments prescribed minimum standard criteria used in our study were: child care homes must have enough resources to run for three years (so the useful life time of three years has been used). Similarly, a minimum of ten children should be supported by the child care with minimum of four staffs.

\subsection{Safe and secure housing}

Using minimum standard guideline for child home of the Central Child Welfare Board (CCWB), an engineer working under Ministry of Local Development was requested to construct a cost estimate for a safe and secure housing. Land price was an averaged value obtained from a Village Development Committee (VDC) Office. A discount rate of $10 \%$ was an accepted rate for calculation in most market setting of Nepal, government organizations including ministries itself and facilitated comparison.

\subsection{Basic consumption}

Basic consumption includes consumption of food, clothing and foot wear; the school uniform should also be understood to be included in this consumption figure. The survey findings of Central Bank of Nepal: "Nepal Rastra Bank" was extrapolated for this purpose. The survey report was entitled "Household budget survey-Nepal, Mid-November 2005 - Mid November 2006" (13). For a robust calculation a mix of economic calculation along with use of unit proportionate method was used to find the individual consumption of a child. Since, a child doesn't consume as much as an adult, a method was needed to bridge this gap. The consumption equivalency scale14, 15, 16 was first choice for use of estimating consumption pattern but since the consumption values were derived from a secondary source, the source held little information by which the consumption estimates could be derived in relation with children only. Therefore, consumption equivalency scale has not been used but a unit proportionate method has been adopted which is the next best available method to estimate for consumption.

\subsection{Care givers time}

Every child should get $100 \%$ supervision all day long duringschool and out of school as well. In this regard, time going to school was differentiated from the time not going to school and holidays. 
For this an average estimate of public holidays, school vacations was used, the need of average sick leave of child at school would also be estimated but due to lack of proper information we relied on holidays estimate to cover that sick leave.

Now, the task was to calculate opportunity cost of care-givers time. As opportunity cost concept implies to gain an total of societal cost estimate due to many practical problems this was not possible, for e.g.: an opportunity cost of an individual working at a child care home would earn NRs. 10,000 per month whereas, equally qualified individual working at a reputed INGO (International Non-Governmental Organization) or in other business would earn a different amount. Practical interpretive problems posing threat to yield an exact calculation of opportunity cost were present. Thus, to overcome this kind of problem, a best way to estimate opportunity cost of care givers time would be to calculate upon average pay scale of the same organization they were working at.

\subsection{Access to services}

Here the services refer to health and education only.

\subsubsection{Access to health Services}

The cost of essential health services were provided free including ARV in case of Nepal. In, reality people were still paying for health services. Most of the times children would present with common disease but of complex magnitude (common diseases coupled with many other diseases, for e.g. child with HIV having diarrhea coupled with pneumonia) in order to properly manage these disease and conditions, cost was involved and in most cases-invariably a significant amount of money was involved. For estimation, financial records revealed that some portion of money was allocated for medical expenses at each model of care. Some model dedicated a larger amount whereas others dedicated a smaller amount. A statistical mean of those values was taken to facilitate computation of minimum standard.

\subsubsection{Access to Education}

The constitution of Nepal recognizes education as a fundamental right. Education fees up to class five has been levied-off by government including course books. Though, a small amount of exam fee has to be paid by the students/ parent. At times supplies of books are not consistent and enough for all students, as a result-many student end up paying for books as well. The children considered under this study were of age group attending up to class ten or School Leaving Certificate (SLC) level. Travel cost to school has also been exempted as government is keen on expanding reach of education for every child; most part of the country is still aloof from roadways, thus many students travel on foot and calculation of this distance-time varied hugely. It was witnessed that none of the child care model sent their children to government school. Most would send their children to private schools thus an estimate of private school fee structure had to be taken into cognizance but this again created a practical problem; private school fees structure varied significantly. Thus, for practicality purpose; Fee structure of government school was used. They were turned into cost for ten years and then averaged for a year, to yield an economic accuracy.

\subsection{Limitations}

Study sites varied from geography, disease prevalence, cultural variations, available resources and networks. Comparisons were limited without any control over those contextual variables. While evaluating the model of care for children affected by HIV/AIDS in Nepal; it was an irony that none of the child care home run by government looked after CABAs. Therefore, cost of providing care for CABA under government run institution's expense and quality standards could not be assessed. Uncertainty analysis for economical data has not been performed due to the very nature of data.

\section{Approaches to care}

In case of Nepal, our study identified community based child care model, home based care and comprehensive care model as popular and available model of care for CABA out of six possible care models all over world:

Figure 1: Models of care

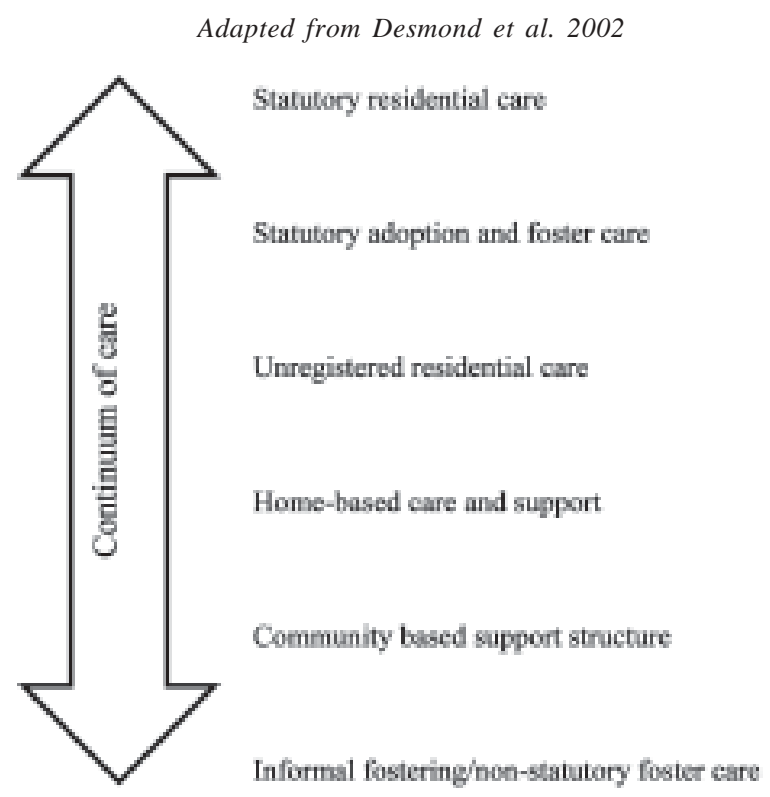

\subsection{Statutory residential care}

"Traditional children's homes, reform schools and places ofsafety all fit into the model of statutory residential care. These are legal, formal institutions that function with government support and supervision. Residential care facilities tend to be large and staffed by many different caregivers. These facilities often face the difficulty of being constitutionally obliged to accept HIV-positive children without being able to know their HIV status, or provide complex and costly care 
that is required."(3) In case of Nepal Statutory residential care doesn't accept children affected by HIV/AIDS (discussed further in discussion section).

\subsection{Statutory adoption and foster care}

"Fostering requires a person appointed by court to perform the role of a surrogate parent and to take full custody of the child. The place of abode is almost always the home of the foster parent. Child Welfare Societies are the state-appointed authorities managing adoption and foster placements. It also includes recruiting to screening parents as well as matching and placing children." (3) The study found no such provision existing in Nepal for CABA.

\subsection{Unregistered residential care}

"Non-statutory residential care provides housing that is often outside the child's community of origin. As the legal status of these homes is unclear, oversight and monitoring of care in the homes is not legally required unless a child has been placed there by a court order." (3) This model of care was not available in Nepal.

\subsection{Home-based care and support}

"Home-Based Care Initiatives (HBCIs) provide services to households of people living with AIDS, TB, disabilities and injuries or other chronic illnesses. Community home-based care models recruit community members to visit and care for needy people in their homes. These HBCI models can either have a community base or an institutional base. Most HBCIs are independent organizations registered as NGOs and are therefore guided by a constitution and board of management. Many have access to donor funding." (3) This care model was most popular child care model in Nepal. One study site identified itself with comprehensive institutional model; it was not fundamentally different from home based care and support instead it had more care components guiding to better nutrition, education, healthcare and socialization of children. Therefore, it has been treated as a separate care model in the study.

\subsection{Community-based support}

"Community organizations in this model category offer support to indigenous, informal caregivers. Their focus varies between emotional support, information provision, advice, advocacy, donations and income generation programs. Generally, CABAs stay in their communities of origin and are cared for by family and members of the same community. Within this approach a variety of organizational structures exist. Some organizations have a constitution, a board of management, staff structure and government registration. Others are completely voluntary, often associated with religious groups and tend to be more charity oriented and are unlikely to be registered in any way." (3) We have found one and only such care providing organization in Nepal.

\subsection{Informal fostering/Non-statutory foster care}

"In this approach, community members assume the responsibility of caring for vulnerable children living among them. Kinship obligations, community preservation and a sense of personal calling motivate caregivers. There is no organizational structure, and networking depends on available resources. This model of care is very common in rural areas where access to services is more difficult than in urban areas." (7) This care model was not found in Nepal.

\section{Results and discussions}

Table 1: Cost effective analysis for three models of care

* failed to meet material minimum standard of care.

a March 12, 2011 Exchange rate 1 NPR=72 US\$ (http://www.xe.com/

\begin{tabular}{|c|c|c|c|}
\hline Models of care & $\begin{array}{l}\text { Actual childcare } \\
\text { costs per month }\end{array}$ & $\begin{array}{l}\text { Minimum standard } \\
\text { childcare costs per } \\
\text { month with house } \\
\text { on lease }\end{array}$ & $\begin{array}{l}\text { Minimum standard } \\
\text { childcare costs } \\
\text { per month with } \\
\text { house ownership }\end{array}$ \\
\hline $\begin{array}{l}\text { Comprehensive } \\
\text { institutional model }\end{array}$ & $\begin{array}{c}42,602.06^{\mathrm{b}} \\
(\text { US } \$ 591.69)^{\mathrm{a}, \mathrm{b}}\end{array}$ & $\begin{array}{c}8,666.97^{\mathrm{b}} \\
(\text { US\$120.37) }\end{array}$ & $\begin{array}{c}84,921.71^{b} \\
\text { (US\$1179.46)a,b }\end{array}$ \\
\hline $\begin{array}{l}\text { Home based care } \\
\text { and support }\end{array}$ & $\begin{array}{c}9,269.52^{\mathrm{b}} \\
(\text { US\$128.74) })^{\mathrm{a}, \mathrm{b}}\end{array}$ & $\begin{array}{c}9,215.44^{\mathrm{b}} \\
(\text { US\$127.99) }\end{array}$ & $\begin{array}{c}84,970.18^{\mathrm{b}} \\
(\text { US } \$ 1180.13)^{\mathrm{a}, \mathrm{b}}\end{array}$ \\
\hline $\begin{array}{l}\text { Community based } \\
\text { care with Micro- } \\
\text { Income generation }\end{array}$ & $\begin{array}{c}6,763.44^{*} \\
\left(\text { US\$93.93) }{ }^{a}\right.\end{array}$ & $\begin{array}{c}5,402.17 b \\
\text { (US\$ 75.03) a, b }\end{array}$ & $\begin{array}{c}84,414.91 b \\
\text { (US\$1172.42) a, b }\end{array}$ \\
\hline
\end{tabular}

$? \mathrm{c}=\mathrm{NPR}) 17$

b Including medical cost associated with child's HIV status.

Table 1 describes the costs of three standards of care. These include actual childcare costs per month, Minimum standard childcare costs per month with house ownership and minimum standard childcare costs per month with house on lease. One of the models failed to meet minimum standard of care, while one was performing at nearly five times minimum standard cost whereas the other one was just meeting minimum standard of care.

Analysis was refined to include more comparable cost of minimum standard of care; other differences still exist in services offered. This comparative analysis also takes into account for differences in cost of care.

Table 2: Differences in structural cost of care (compared with government minimum standards)

The result outlines expensive nature of more formal models, particularly at comprehensive institutional model. Here, we

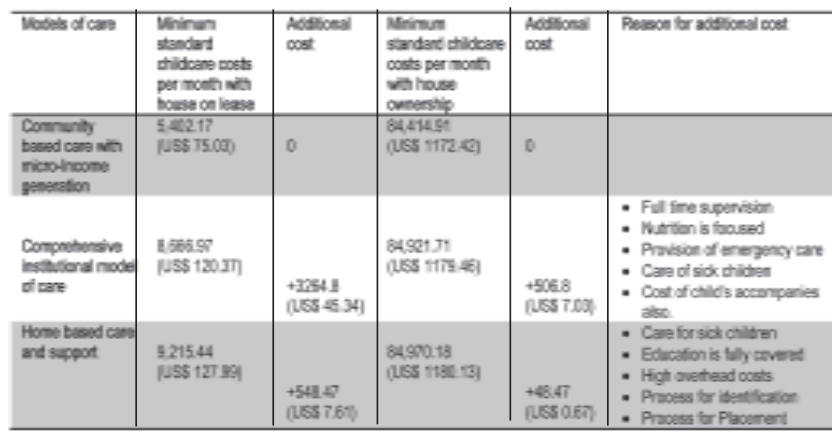

need to account for the wide spectrum of services they are offering. At both residential sites, we got a clear picture that children were placed there because they had nowhere to go. Children were often rescued from societies, when their parents 
died or their family was banned from society. Despite the cost appearing high, residential care appear as the only alternative to life for such children. This diminishes the validity of comparing costs of different models of care.

The most cost-effective models of care were obviously community based care models. In case of Nepal, this model was also seemed to be conducting some income generation activities of its own which greatly helped them to be selfsufficient. It was also found that socialization was also natural to children of this care model. However, this model of care was found to be struggling to provide adequate material care and was in dire need of additional external support. From the case study of care models two avenues of financial support was traced out; one from charitable national and international institutions and the other from income generation activities. The community based organization in our study already had children identification network in place and has already started drawing children from remote areas of the country. Popularity of this model was attributed to easy admission, family environment, normal household activities like agriculture and animal husbandry to keep the children and parents engaged without any obligations. On the contrary, formal models of care examined in this study were expensive but they do provide a place for children to go in emergency situations and especially when a severely ill child needs care. Another striking finding of this study: HIV/AIDS was a priority one disease in government health agenda; government run child care homes didn't accept children with HIV/AIDS. When asked about this issue, government officials said that currently they were unprepared for caring needs of CABA and they were planning to expand their services to include CABA into their care system in near future.

Caring of CABA is undoubtedly a daunting task with ethical questions arising each time when resources have to be divided to deal with different contingencies. For e.g. deciding whether to invest in Intensive Care Unit (ICU) for a terminally ill child or invest in supportive care for other illness of CABA. The need for continuum of options of care is inevitable; however it would be disastrous to rely on only one model of care. Failing to provide a multitude of care option would leave children with the only option to fend for themselves.

\section{Conclusions}

Children have right to be cared, despite their HIV status. The needs of CABA are varied due to nature of HIV and AIDS impacting not only physically but socio-economically. Child care models though are many in number for orphan children but not much for children affected with HIV and AIDS. Though history of AIDS in Nepal dates back to 1988, only three models of care has come forward to provide care for CABA, this reflects inaction from government and nongovernment side. For instance, government of Nepal still doesn't provide care for CABA children under its child care home. Therefore, a child still has to depend on their extended families and tutelage of caring institutions.
Cost-effective analysis in this study verified the potential of community-based models to provide care at significantly lower cost over other models. However, it is undeniable that sometimes a child has nowhere to go (completely abandoned) including the child doesn't want to stay with extended family. At those times residential option can act as a temporary shelter for children.

Though, community based care are clearly the most costeffective models of care than other existing models of care it is also essential to understand: continuum of care is often missed by one model so various models still need to improvise in order to provide continuum of care for children.

\section{Recommendations}

\subsection{For community/NGO/INGO/other development partner}

Create a networking system that builds on the success of previous networks for identification and placement of child in relevant care models, Enhance activities and co-ordination between various child care models, Treatment is a better standpoint to fight HIV EPIDEMIC but to fight HIV RISK we need prevention programs, Adopt universal access for opportunity mindset.

\subsection{For policy implication/ Government}

The treatment cost of other illness has been increasing so, now would be the best time to incorporate ARV treatment regimen and other HIV treatment guideline into elements of Primary Health Care with giving continuance to "free essential health care", National Centre for AIDS and STD Control should establish a child care wing which should be held responsible for child care patterns and practices, Government should also focus on "safety net" for children who fail to reach to such care homes, Promote community based childcare models with income generation activities.

\section{Acknowledgements}

We would like to extend our deep appreciation for Dr. Chris Desmond of FXB Center, Harvard School of Public Health, Dr. Megharaj Dhakal, Under Secretary of Ministry of Health and Population Nepal for their guidance and support. Gratitude to Staffs and institutions which were pivotal to study: Mr. Rajiv Kafle, NAPAN+, Mr. Vuvan Dahal, Navakiran, Mr. Gopal, Keta-keti Ashram, Ms. Ranju Pandey, FNC-Nepal, Ms. Laxmi Adhikari, Aakura. Erg. Dilliram Bhatta, Ministry of Local Development Nepal, Mr. Manish Shrestha, Global Village Information Centre, and my helpful friends Mr. Navaraj Bhattarai, University of Tromso Norway, Ms. Nirmala Sharma and the Children of course.

\section{References}

1. Global Report: UNAIDS report on the global aids epidemic 2010. Geneva, Switzerland: UNAIDS;2010. http://www.unaids.org/ 
documents/20101123_GlobalReport_em.pdf. Accessed March 12, 2011.

2. The World Bank Web site. http://www.worldbank.org/np. HIV/ AIDS in Nepal. Accessed on August 8, 2009.

3. Salaam, T. AIDS Orphans and Vulnerable Children (OVC): Problems, Responses, and Issues for Congress, In: CRS Report for Congress. Foreign Affairs, Defense, and Trade Division. 2005.

4. Universal Access for Children Affected by AIDS in Nepal (UCAAN). Press Release: UNICEF, FHI, NAP+N \& USAID Initiate a Partnership. Kathmandu, Nepal; November 28, 2007.

5. Government of Nepal. The state of children in Nepal. Kathmandu, Nepal: Ministry of women, children and social welfare, Central Child Welfare Board; 2007.

6. National Centre for AIDS \& STD Control(NCASC). National estimates of HIV infections 2009-Nepal. 2010.

7. Desmond, C., Gow, J., Loening-voysey, H., Wilson, T.,Striling, B. Approaches to caring, essential elements for a quality service and cost effectiveness in South Africa. In: Evaluation and program planning. 2002;25:447-458

8. UNDP. The Interim constitution of Nepal, 2063 [2007], Fourth Edition. Simon Printers \& Traders, Nepal. 2010. 64, 72-78

9. Central Bureau of Statistics (CBS). Population census 2001 of Nepal. 2002 .

10. Government of Nepal. "Minimum standard working guidelines for HIV/AIDS infected children care homes, 2065 B.S. (2009 A.D.)"[Draft].Kathmandu, Nepal: Central Child Welfare Board; 2009.

11. Government of Nepal. "Minimum standard for conduction and management of child home, 2060 B.S. (2004 A.D.)" Kathmandu, Nepal: Central Child Welfare Board; 2004.

12. Drummond, M.F., Stoddart, G.L., Torrance, G.W.,Methods for the economic evaluation of health care programmes. Oxford: Oxford Medical Publications. 1997.

13. Nepal Rastra Bank. Household Budget Survey. Baluwatar, Nepal: Nepal Rastra Bank; 2009:19-25.

14. Browning, M., Chiappori, P.A., Lewbel, A. Estimating consumption economies of scale, Adult equivalence Scales, and Household bargaining power. http://citeseerx.ist.psu.edu/viewdoc/ download?doi=10.1.1.172.6738\&rep=rep1\&type=pdf . Accessed on March 12, 2011.

15. Wilke, R. A., Semiparametric estimation of consumption based equivalence scales- the case of Germany. 2005. http:// home.arcor.de/ralf_wilke/equivalence\%20scales.pdf . Accessed on March 12, 2011

16. Michelini, C., Equivalence scales and consumption inequality: a study of household consumption patterns in Italy.Massey University. http://www.eco-dip.unimi.it/uploads/wp/wp95.pdf . Accessed on: March 12, 2011

17. Interactive Currency Converter. NPR to USD. http:// www.xe.com/?c=NPR . Accessed on March 12, 2011. 